\title{
Development of a Repairable Heat Exchange for Disposal Considerations for Household and Municipal Waste
}

\author{
Maxim Alexandrovich Lobanov', Eldar Rinatovich Abdeev', Vitaly Vyach- \\ eslavovich Chelnokov², and Rinat Gazizyanovich Abdeev ${ }^{1}$ \\ ${ }^{1}$ Bashkir State University, Ufa, Russia \\ ${ }^{2}$ RCTU them. DI. Mendeleev, Moscow, Russia
}

Corresponding Author:

Maxim Alexandrovich Lobanov

lobanov@bgutmo.ru

Published: 31 December 2020

Publishing services provided by

Knowledge E

(c) Maxim Alexandrovich

Lobanov et al. This article is

distributed under the terms of

the Creative Commons

Attribution License, which

permits unrestricted use and

redistribution provided that the

original author and source are

credited.

Selection and Peer-review under the responsibility of the TECHNOGEN-2019 Conference Committee.

\section{Abstract}

Evolvent form can be applied in the new design of an air cooler and shell and tube heat exchanger used in the oil and gas industry. The air cooler is constructed as a vertically cylindrical multi-section with the evolvent-profile tube row in tube bundle. Tubes have a U-shape form for solving the problem of destruction from linear thermal expansion during maintenance. The dismountable shell-and-tube heat exchanger has an evolvent-profile tube bundle. The advantage of this heat exchanger is its dismountable construction, maintainability and energy efficiency. This is enhanced by the construction of the heat exchange element, which consists of stainless corrugated flexible tubes. Dismountable construction is achieved by a set of flanges and fittings. The energy efficiency of the heat exchanger is determined by thin wall of the corrugated tube, which is $0.3 \mathrm{~mm}$, whereby a heat energy will be transferred faster from a hot stream to cold liquid. Also, energy efficiency is enhanced by tight packing of the tube bundle, which contributes to increase heat transfer area per unit volume. Such solutions contribute to the promotion of more efficient technological equipment and promising ideas for further development and improvement of technical and technological complexes.

Keywords: tube, heat, corrugated, flexible, evolvent, construction

\section{Welded and Collapsible Heat Exchangers}

Most of the known heat exchangers do not have a removable heat exchanger elements, which is bad for their maintainability. For example, in shell-and-tube apparatuses, heatexchange tubes are attached to the tube sheet by rolling and welding. In case of failure of the pipe, its choke. Among the new developments there are designs with collapsible tube bundles, but almost all of them have one significant drawback - the use of a large number of flanges on the casing. This increases the metal consumption of the apparatus and introduces additional requirements for reliability and tightness of flange joints. 
Plate heat exchangers are also known in which special gaskets of complex shape are placed between the plates. After disassembling and repairing the heat exchanger, the gaskets require replacement, which is quite costly for the owner of the device.

A shell-and-tube heat exchanger has been developed, which is devoid of the above disadvantages.

\section{Scopes of the New Heat Exchanger}

The heat exchange element is a corrugated stainless steel pipe. According to the product passport, the maximum working pressure is $1.5 \mathrm{MPa}$, the maximum working temperature is $150^{\circ} \mathrm{C}$. The heat exchanger under consideration covers many areas of industry, with the exception of the oil industry, due to the ban on the use of pipes with welds according to GOST R 53677-2009.

\section{The Design of the Heat Exchange Section}

The apparatus consists of one or more heat-exchange sections located in the housing [1]. The case itself has several design options, depending on the following initial parameters:

- internal pressure;

- maximum working temperature;

- coolant costs;

- number of heat exchange sections;

- the presence in the design of the "pipe-in-pipe" heat exchanger.

The heat exchange section consists of a tube bundle and a frame for it. The tube bundle is made of corrugated steel pipes (Fig. 3). This bundle is placed in a frame consisting of a collector, annular partitions, studs, nuts and restriction pipes (Fig. 4). The annular partitions have three types: with a cutout near the casing, with a cutout near the collector and thickened extreme partitions. Also among the structural elements of the heat exchange section there are fitting connections and ring gaskets.

\section{Benefits of the New Heat Exchanger}

The collapsible design is achieved through a threaded connection. Each pipe is connected to the distribution chamber using a gasket fitting. Corrugated pipes have two types of fitting fastening - with pipe rolling and union nut or with the use of a threaded 


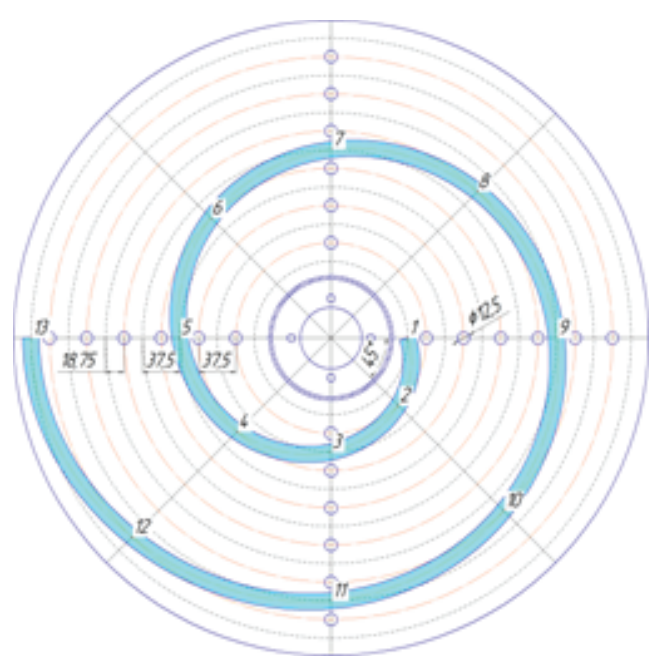

Figure 1: The shape of the heat exchange pipe, curved according to involute

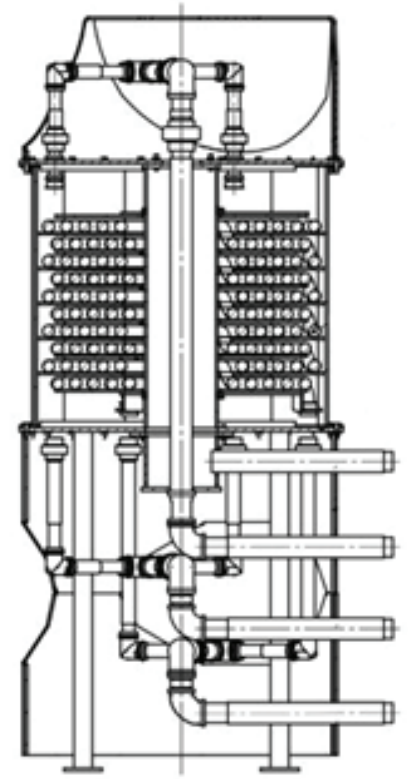

Figure 2: Sketch of a household collapsible involute-profile heat exchanger

fitting, union nut and circlip with an annular gasket. If you use the first case, then to the holes in the tube sheet, it is necessary to weld the pipes with external thread under the thread of the union nut. In the second case, it is enough to make holes in the tube sheet to place a fitting in them, which on the reverse side will be twisted with a nut with an annular gasket. This technical solution allows you to quickly replace the entire heat exchange section with a new one, while a damaged or clogged pipe is replaced in the dismantled waste section.

Depending on the length of the casing or customer requirements, the number of heatexchange sections can be varied. Two sections are able to connect with each other by mounting one extreme thickened partition to another using studs and nuts similar to 


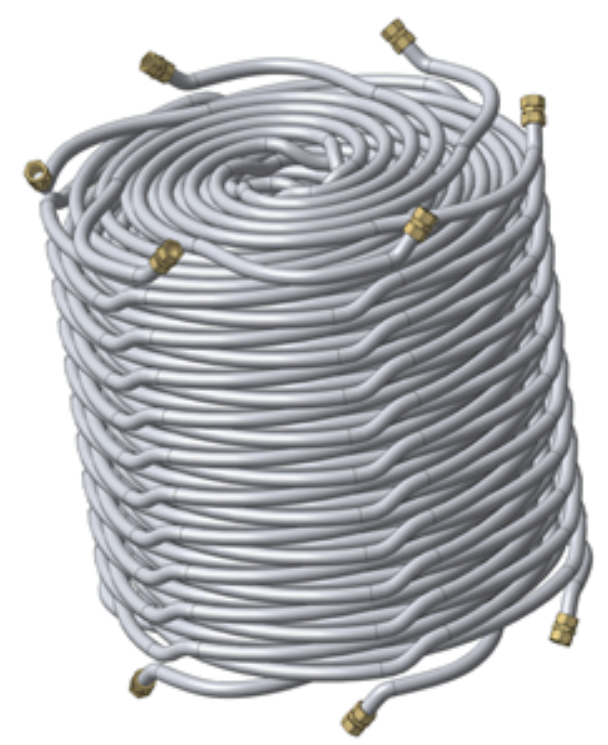

Figure 3: Model of involute profile tube bundle

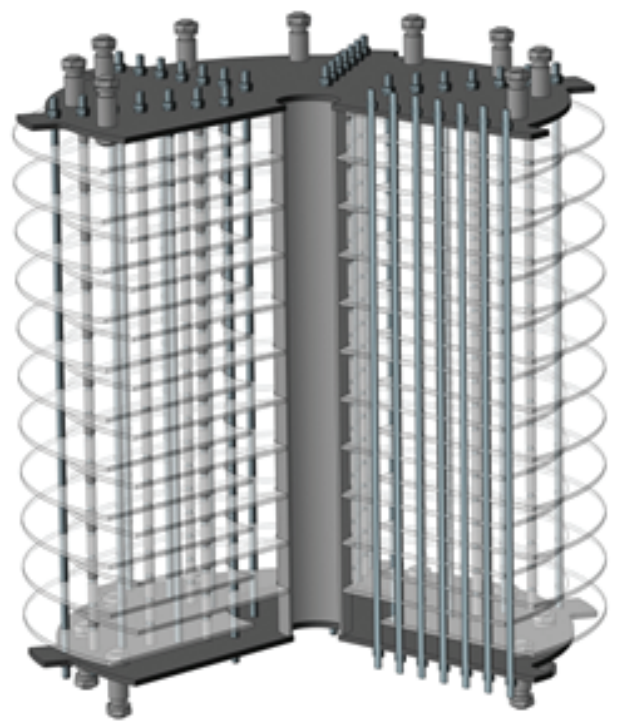

Figure 4: Frame for a tube bundle

flanges. The corrugated pipes themselves of the sections mounted to each other are connected using a sleeve, thereby forming a multi-sectional structure. Between the two sections are placed restrictive pipes. Such design and technological solutions make it possible to increase the number of heat-exchange sections in an existing apparatus at the discretion of the customer. For this, a new cylindrical shell is additionally placed in order to expand the internal space under the new section.

Maintainability and reliability are due to the fact that the heat exchange elements are corrugated thin-walled metal pipes. They are not scarce, and when disassembling, repairing and assembling, little money is spent on replacing ring gaskets. The characteristic bending of the heat exchange tubes along the involute protects their joints 
from destruction due to thermal expansion of the material under the influence of high temperatures.

The efficiency of the apparatus is due to the following features of the corrugated pipe: a thin wall has a positive effect on heat transfer; corrugations contribute to the intensification of heat transfer due to flow turbulence at low speeds; corrugations play the role of stiffeners, so these pipes are stronger than smooth-walled with the same wall thickness; the pipes retain a circular cross section in the bending zone; high alloy steel is not subject to corrosion; the pipe can easily take a curved shape without the use of specialized equipment.

Dense packing of the tube bundle also contributes to energy efficiency, contributing to an increase in the heat transfer area per unit volume. For information, in shell-andtube heat exchangers with smooth straight pipes, such a close arrangement of pipes is unacceptable due to the strength of the tube sheet.

Advantages of tube bundle shape: the tube bundle does not require any compensators from the thermal expansion of the material under the influence of high temperatures; $\phi$ the form of involutes remains equidistant, i.e. parallelism of pipes in any section of the tube bundle from the center to the periphery [2]; possible to fill a large space housing a small amount of heat exchange tubes; on the basis of the large length of the pipes, the working medium travels a long way from one end of the pipe to the other and, therefore, effectively transfers / takes heat.

The design of the shell-and-tube heat exchanger is devoid of the disadvantages of the known prototypes, which makes it possible to introduce it into production and further operation.

This work was supported by the RFBR grant No. 18-29-24178

\section{References}

[1] Lobanov, M. A. and Latypov, G. R. (2018). Modernization of a Double-Circuit Test Bench for Assessing the Thermal Efficiency and Hydraulic Resistance of Heat Exchangers. Presented at I All-Russian Scientific-practical Conference with International Participation "Actual Problems of Mechanical Engineering". Ufa: BashSU, pp. 67-71.

[2] Abdeev, E. R., et al. (2012). The Study of Energy Efficiency of Various Layouts of Tube Bundles of Air Cooling Apparatus. Oil and gas business, vol. 6, pp. 404-418. 